\title{
Journal of Librarianship and Information Science
}

How implementation of bibliometric practice affects the role of academic libraries

Fredrik Åström and Joacim Hansson

Journal of Librarianship and Information Science published online 13 September 2012

DOI: $10.1177 / 0961000612456867$

The online version of this article can be found at:

http://lis.sagepub.com/content/early/2012/09/11/0961000612456867.citation

\author{
Published by: \\ (SAGE \\ http://www.sagepublications.com
}

Additional services and information for Journal of Librarianship and Information Science can be found at:

Email Alerts: http://lis.sagepub.com/cgi/alerts

Subscriptions: http://lis.sagepub.com/subscriptions

Reprints: http://www.sagepub.com/journalsReprints.nav

Permissions: http://www.sagepub.com/journalsPermissions.nav

>> OnlineFirst Version of Record - Sep 13, 2012

What is This? 


\section{How implementation of bibliometric practice affects the role of academic libraries}

Journal of Librarianship and Information Science $0(0) 1-7$

(C) The Author(s) 2012

Reprints and permission:

sagepub.co.uk/journalsPermissions.nav DOI: |0.| |77/096|0006|2456867 lis.sagepub.com

\author{
Fredrik Åström \\ Lund University, Sweden
}

Joacim Hansson

Linnaeus University, Sweden

\begin{abstract}
This article discusses potential consequences of implementing bibliometrics as an institutionalized practice in academic libraries. Results are reported from a survey among libraries in Sweden with organized bibliometric activities. Incorporating bibliometric activities is one way of redefining and widening the role of the library. Implementation of bibliometric practice is motivated by ambitions to provide more complete scholarly communication-related services, as well as to increase the visibility and status of libraries. Underlying reasons are professional competencies such as metadata and bibliographic database management; and bibliometrics being strong within library and information science. Incorporating bibliometrics in academic libraries is also seen as a way of widening the professional profile of librarianship. The new role should, however, also be considered from the viewpoint of potential changes in how academic libraries are perceived when incorporating a monitoring function through bibliometric analyses of research performance in addition to traditional service-oriented functions.
\end{abstract}

\title{
Keywords
}

Academic libraries, bibliometrics, profession, research evaluation, role of libraries/librarianship

\section{Introduction}

Over the last few decades, there have been significant changes in systems of research management and policy, where evaluation of research outcomes are increasingly linked to the allocation of research funds on various levels - from individual scholars, to institutions and national systems for academic research, such as the national level distribution of government funds between publically funded universities. One important part of this change is how bibliometric methods to an increasing extent have become utilized to identify quantitative indicators for academic productivity and quality (Whitley and Gläser, 2007). Also over the last few decades, the role and nature of librarianship and information management has been discussed, both as a field of professional practice and as a field of scientific inquiry (e.g. Nolin and Åström, 2010; Schreiber and Elbeshausen, 2006). One recent example of this is how, since the expansion of the Internet over the last two decades, searching for information has increasingly become something done by the individuals needing information themselves, rather than by information professionals.
Simultaneously, the development and evaluation of tools for searching has become an activity of, for example, computer scientists rather than information retrieval scholars in the field of library and information science (LIS). This has led to a perceived need for the LIS professionals to redefine their professional roles.

In LIS, bibliometrics has been an important field of research for decades (e.g. White and Griffith, 1981; White and McCain, 1998) and its presence in the wider contemporary LIS field seems to be expanding at a rapid rate (Åström 2007). During the 2000s, bibliometrics has become of increasing interest not only in the LIS field of research but also to professional practitioners in libraries, primarily in the field of research and higher education (Ball and Tunger, 2006; Brennan, 2008). This is perhaps a response to the perceived need for librarianship to redefine its role and

\section{Corresponding author:}

Joacim Hansson, Linnaeus University, PO Box 45I, Växjö 35I95, Sweden. Email: joacim.hansson@Inu.se 
expand its competencies. Over the last few years, university libraries in Sweden, as well as in a number of other European countries, have started offering bibliometric analysis to provide background material for the evaluation of research performance and the distribution of funds, both at institutional level and within individual faculties and departments (Carlsson and Hällgren, 2008; Gerritsma et al., 2010).

The aim of this paper is to discuss how taking up bibliometric analysis as an institutional practice may have a potential effect on the role of the library and its relation to the wider organizational context of the university. More specifically, these issues will be discussed from the viewpoint of the following questions:

1. What is the background of libraries and librarians deciding to develop competencies in bibliometrics and to take on responsibilities for performing such analyses?

2. What are the potential effects of these changes on the professional role and identity of academic librarianship, and how does this new role relate to other functions of the librarians and the libraries?

3. What are the potential effects of these tendencies on the relation between the library and the wider university organization and in relation to the scholars as well as to university administrators and policy makers?

The basis for the discussion of these questions will partly be the literature on the subject. To get further indications on how this development is looked upon by the professionals, a small-scale survey has been conducted, distributed to the Metrics list, an email listserv administered by the Bibliometrics Group (a forum for librarians working with or interested in bibliometrics at Swedish university libraries within the Forum for Head/University Librarians in the Association of Swedish Higher Education).

\section{Related literature}

Since the second half of the 2000s, Swedish university libraries have to an increasing extent started building institutional competencies in bibliometrics (Carlsson and Hällgren, 2008). Within the Forum for Head/University Librarians in the Association of Swedish Higher Education there is a working group for bibliometric, informetric and scientometric issues, established in the spring of 2007. Courses on bibliometric methods and applications are offered for librarians, organized both locally and on a national level, e.g. by the aforementioned Bibliometrics Group, led by experts from the Swedish Research Council, the LIS research community and library faculty with long experience of bibliometric analysis. Perhaps the most manifest expression of this trend is that many university and university college libraries have created positions explicitly titled 'bibliometrician'. This development has not been limited to Sweden; similar trends can be found internationally, for example in Germany and the Netherlands (Gerritsma et al., 2010). This development has been discussed by, for example, Rafael Ball and Dirk Tunger (2006) as well as Patricia Brennan (2008). As a result, university libraries have started offering bibliometric analysis to provide background material for the evaluation of research and the distribution of funds for the university as a whole, as well as for faculties and departments within the university. An important question relating to this is what inspired it.

One factor behind the development of bibliometric activities in libraries is the perceived need for a redefinition and widening of the professional roles of academic librarians within the wider university organization. Traditionally, librarianship has to a large extent been focused on issues concerning the acquisition and organization of library collections, as well as searching and retrieving information for the users of the library. However, with online access to both search tools and the information per se, it is easier for users to do many of the search- and retrieval-related tasks themselves. At least to some extent, it could seem that some of the services related to one of the core competencies of librarianship are no longer in high demand by users of the library. Combined with new practices of publications of research results, user behaviour and competencies have created a need for redefinition of librarianship towards an increasing emphasis on the professional role on issues such as information literacy and other pedagogical aspects related to searching information. A stronger integration of the librarian in the academic process has been called for (Hansson, 2010). This development is parallel with developments in LIS research, in which systems-oriented information retrieval research has decreased, whereas behavioural and social aspects of information seeking and usage have increased ( $\AA$ ström, 2007).

University libraries, at least in Europe, are also increasingly focused on the development of knowledge and services related to scholarly communication other than simply searching and retrieving scholarly information. One important part of this is an increased activity in the dissemination of research. University libraries in Europe have become strong proponents of Open Access (OA) publishing and work actively to support $\mathrm{OA}$ initiatives such as hosting $\mathrm{OA}$ publishing tools and developing directories of OA journals. Related to this is how university libraries increasingly have become responsible for the development and maintenance of local repositories and publication databases. These local repositories can be seen from two different perspectives. On one hand, they can be seen as being related to OA issues, on the other hand, the repositories can be and are being used as data-sources for quantitative analysis of research output in the form of publications (Ayris, 2011). 


\section{Growing interest in bibliometrics}

Bibliometrics is a well-established part of library and information science research (e.g. Narin and Moll, 1977; White and McCain, 1989; Wilson, 1999), and the use of it in libraries, for example for collection development and management, is also a well-known practice, not the least in relation to digital library development (Dikeman, 1975; Jimenez-Contreras et al., 2006; Kishida, 1995; Nicholson 2003). Academic libraries applying bibliometric methods and techniques for research evaluation purposes, however, is a more recent phenomenon (Ball and Tunger, 2006; Brennan, 2008; Carlsson and Hällgren, 2008; Gerritsma et al., 2010).

One important aspect of the increasing interest in bibliometrics, in libraries as well as in academia in general, is the growth in use of bibliometrics to evaluate research performance, 'especially in university and government labs, and also by policymakers, research directors and administrators, information specialists and librarians and researchers themselves' (Pendlebury, 2009: 2). Conferences, workshops and courses in bibliometrics, scientometrics and science and technology indicators are increasing both in number and in size. The allocation of research funds in the academic community and research policy in general is increasingly guided by such analysis. This is a development occurring on both local and national levels in many countries such as Sweden, Norway and Australia, to name just a few (e.g. Vanclay, 2011).

This, in turn, has a background in a shift in how publically funded academic research is perceived and managed by national governments, a shift including more focus on, for example, strategically oriented research policies and accountability. One aspect of this is the increasing importance of the systematic evaluation of research, both for strategic decisions on the future and accounting for past spending. This has, in many countries, led to the development of national large scale systems for research evaluation (Whitley and Gläser, 2007).

The use of biliometric indicators for the evaluation of local faculties and departments is becoming a common practice. It is here university libraries come into play. As mentioned earlier, there are a number of reasons for having university libraries being the organizational locale for bibliometric activities. One is that bibliometrics is an important part of LIS research, which makes it quite natural to apply it in professional practice. Another important reason is that professional competencies of librarians include having long-term experience in developing and handling bibliographic data, and systematically dealing with large document sets. A third reason mentioned is how, in many cases, libraries have been in charge of developing and hosting institutional repositories, thus having immediate access to an important data source for measuring productivity through analysis of publication frequencies.

\section{Methods and materials}

In Sweden today there are 48 institutions of higher education and research. Of these, 18 institutions have some form of organized bibliometric activity, mostly in the university library (Carlsson and Hällgren, 2008). To get a sense of the state of bibliometric activities at university libraries, a survey was posted to the Metrics mailing list. ${ }^{1}$ Metrics is an online listserv serving as a discussion forum for Swedish university libraries staff members, as well as other people in Swedish academia, with an interest in bibliometrics. The list is managed by the Bibliometrics Group within the Forum for Head/University Librarians in the Association of Swedish Higher Education and in September 2009, the number of members of the mailing list was 71 . The purpose of the survey was to:

- investigate the nature and width of bibliometric activities at Swedish university libraries;

- collect information about on whose initiative and/or mandate bibliometric analyses are performed at university libraries;

- gain insight about the positive and negative consequences for the libraries, getting involved in bibliometric activities.

Replies from nine of the 48 institutions for higher education in Sweden was considered an acceptable rate, considering that there are 18 universities with organized bibliometric activities, of which 14 are located within the university library. Several libraries did not submit answers due to poor or recently institutionalized bibliometric practice. Still, the limited number of replies, which is largely due to the limited academic library environment in Sweden, means that the findings can be used primarily as an indication of practice rather than as proper statistical results which can be generalized. These indicative results may, however, be useful in continuing analysis and discussions within the research community as well in practical librarianship.

\section{Results}

\section{The organization of bibliometric activities}

The first set of questions dealt with how bibliometric activities at university libraries are organized in terms of the scale of the activities and under whose initiative and mandate they are carried out. The answers, in terms of scale, ranged, from dealing with bibliometric issue either on a 'when there is time to spare' or 'as needed' basis, to fulltime positions. Where full-time positions are indicated, either one or two people mostly undertake this work or it is divided amongst a larger group of positions that also, to some extent, include time for basic research. This range of scale impacts the importance of activities as well. In some 
instances, it means having someone simply monitor the development of bibliometrics and its relationship to research policy. In others, it involves large-scale analysis of the university as a whole, including undertaking basic bibliometric research, methodological development and teaching. At five out of the nine universities there is at least one full-time staff member working with bibliometrics; those with less time allocated are primarily smaller institutions.

As with the size and range of the bibliometric activities, there are also substantial differences in terms of the background of the staff responsible. At one end of the scale, we find librarians with a Masters Degree in LIS, with little or no formal training in bibliometric methods; at the other, staff with $\mathrm{PhD}$ degrees in statistics or other research fields with a strong focus on quantitative methods.

With regard to initiating bibliometric activities in the library, the variations in response are not as large as in terms of bibliometric activities. In most cases, activities are originally initiated by the libraries themselves, but to an increasing extent, and especially at larger libraries, there is also an official mandate from university management to perform bibliometric analysis to evaluate research in different faculties and departments. The variations increase depending on who the libraries see as 'customers' for their bibliometric activities. At the larger universities, with an official mandate for the libraries to do bibliometrics, university and faculty management are to a large extent the commissioning authorities. Smaller institutions tend instead to emphasize disseminating information on bibliometric indicators to individual scholars, research groups and faculty administration, as well as to other librarians, for example.

\section{The nature of bibliometric activities}

All but two of the participating libraries offer some form of bibliometric analysis as a service to other units within the local university, such as management, departments or branches of the university library. Although there are differences, all performed analyses are for the purpose of research evaluation and/or providing background information for the distribution of funds on a local level, i.e. between faculties and departments at the universities. When asked who the libraries perceive as the target 'audience' for the analyses, for whom they actually perform analyses, it is interesting to note a much larger presence of university and faculty management among actual 'customers' than groups of scholars or individuals. Also notable is that one library that actually did not perform bibliometric analysis raised the question whether the library should be participating in evaluating the scholars at the local university.

Although bibliometric analysis for research evaluation is by far the most frequent, examples were given of other types of use. Three libraries report doing analysis for the purpose of mapping research fields, research collaboration by investigating co-authorships, and performing analysis as a service to individual scholars or research groups. Three libraries reported the use of bibliometrics for collection management purposes, where the analyses are primarily for in-house use.

An important part of bibliometric activity - aside from doing the analysis - is providing information to individuals and groups within the university through, for example, seminars and lectures. The purpose of this is to raise awareness of different methods for research evaluation and how they are linked to systems for resource allocation; and through that, for scholars to be able to develop strategies to deal with these systems and methods.

\section{Bibliometric activities: Motivations and consequences}

The third set of questions in the survey addresses two different aspects of bibliometric activities at the libraries. One is the motivations for libraries specifically being responsible for performing bibliometric analysis; and the second, what potential consequences the libraries see in them being the organization within the university performing them.

Answers on the more general issue of why the library should be responsible for organizing bibliometric activities reveal two main lines of reasoning. One relates to the competencies of librarianship and LIS concerned with publication databases, documents and metadata, and experience with bibliographic tools in general. The other concerns the position of the library within the wider university organization. It is considered a stable entity within the university that itself is not affected by the outcome of the bibliometric analysis. For this reason it can take a neutral or objective position relative to the faculties or departments being evaluated. A third line of reasoning that can be seen both as a general motivation for libraries doing bibliometrics, and for individual libraries implementing such practices as part of their agenda, is that bibliometrics is central to the role of the library in contemporary processes of scholarly communication. This includes development and management of institutional repositories as well as having an active role in OA publishing issues. New patterns of publications, with the library as an active part, seem to open up potential for a new and even stronger position in the university's organizational structure. Less frequently stated, but mentioned, by respondents is that bibliometric analysis brings libraries not only a new role in the academic context, but also more attention. As one respondent said: 'library management [is] considering these activities prestigious'.

\section{Opportunities, benefits and risks}

Those surveyed were asked what opportunities and benefits the implementation of bibliometrics brings to the library. Three kinds of answers can be distinguished. The first relates to how bibliometrics becomes an addition to 
responsibilities and widens the competencies of libraries and librarians. This is important at a time when tasks and competencies traditionally associated with librarianship increasingly move into the realm of the users of the libraries. The second kind of response is about how this expanded role has increased the visibility of university libraries in the wider academic context. This is said mainly to come from the development of an increased cooperation with scholars at the university, leading to libraries taking a more active role in different aspects of the research process and scholarly communication. Third, increased cooperation with university management leads to libraries becoming more involved in central university management processes, which is clearly felt to increase the influence and prestige of libraries within their parent institutions.

Might there be any risks in the increase of biblometric activities in university libraries? Well, only one library representative saw no risks what so ever in implementing bibliometrics. Most replies point out a number of risks:

1. One is related to the competencies in the field of librarianship. While a competency concerning bibliographic data, as well as the management of large document collections, is mentioned as a reason for libraries to implement bibliometric analysis, some respondents raised concerns about lack of competency in advanced statistical methods in general and bibliometric indicators in particular.

2. Other concerns mention relations between libraries and scholars if libraries do bibliometric analysis for research evaluation. Do the competencies of the librarians make them legitimate as evaluators of scholars in different fields at the university?

3. A third risk mentioned is the danger of the library being associated with 'bad' results of departments not performing well according to the bibliometric indicators.

These concerns all come down to a sense of danger that the library, being seen as a more active participant in research policy, now turns from being a service or support function at the university to becoming one with an auditing or monitoring function, passing judgment on scholars. Some respondents raise the issue that use of bibliometric indicators for research evaluation is quite controversial in the research community - not least in a country like Sweden, where these kinds of assessments are relatively new.

\section{Conclusions and discussion}

Over the last few decades, both librarianship and LIS as a field of research have gone through a redefinition of their roles and tasks. Some have perceived this as a crisis in librarianship and LIS research, as many activities that traditionally have been part of the core of the field and the profession to an increasing extent have faded into the background or have been performed by others. This has led to the question of how to maintain professional and organizational legitimacy. Maintaining legitimacy includes finding alternative ways of using existing competencies, and at the same time developing new ones. As the academic community today is subject to an increase in systematic evaluations of research systems and institutions, not least in relation to allocation of research funds, new possibilities have been attributed to academic libraries. To meet these, the profession has developed different strategies. One is to take on a more active role in a range of different aspects of scholarly communication. Another, to some extent as a consequence of this, is to start implementing bibliometric analysis as institutional practice.

The aim of this paper has been to analyse and discuss this latter development, by investigating why libraries choose this particular path, and to explore its potential effects. It also examines the effects of libraries doing bibliometrics can have on their role in relation to the wider university organization. The analysis draws from examples of Swedish university libraries, of which an increasing number over the last decade have institutionalized some form of bibliometric practice. Although Sweden is not the only country in which this has occurred, it is one of the countries where the concrete impact of this development is evident in terms of positions, as librarians are explicitly employed to undertake bibliometrics. A brief survey of academic libraries with institutionalized bibliometric activities has provided the analysis with examples of benefits and concerns about undertaking systematic bibliometric analysis.

The expansion of the role of the university libraries and the professional competencies of librarians can be seen as concurrent with the general development in higher education:

- bibliometrics as a field of enquiry has to a large extent been developed by scholars in LIS;

- evaluations of universities are to an increasing extent based on institutional repositories largely developed at, and maintained by, university libraries;

- the implementation of bibliometrics adds to professional competencies such as bibliographic control, knowledge about metadata and the experience of dealing with large document collections; and it fits well with libraries taking on more active roles in scholarly communication processes.

The benefits of this widening scope of activities for libraries have been widely discussed in LIS research. Seldom, however, have the practitioners themselves been asked about it. The role of LIS professionals and the role of libraries become stronger by developing new sets of competencies, both in themselves and in relation to the wider 
university context. It increases the visibility of the library and the competencies of the librarians in relation to the wider university organization. One aspect of this is visibility, in terms of servicing the user by informing about bibliometric indicators and their use for research evaluation and the allocation of funds, thus helping scholars in developing strategies for dealing with a new situation. Another aspect of the visibility is in relation to university management, as the link becomes stronger by executing bibliometric analysis to provide background material for evaluations - thus becoming part of the funding policy process.

From the professional perspective, the widened competencies may carry a potential to increase the status of librarianship, since quantitative evaluation indicators traditionally have been held in high esteem in academia. This is of course something that can be 'put to use' when assisting scholars in developing strategies for dealing with new criteria for the evaluation of their research. From an organizational perspective, the status issue can also be seen in an increased influence on policy processes - here, the influence is more in relation to university management rather than the scholars. This can be seen from the perspective of a shift in the role of the library itself and its relation to the wider university organization on several different levels. An important aspect of this is how libraries are developing from a service function of supplying the scholars with the information, to one monitoring them through the production of statistics on their productivity and impact. This introduces a controlling function in relation to the university's researchers that librarians have not had before. This brings on a shift of 'consumers' from scholars to university management and administration, something which raises questions about the legitimacy of the libraries within the universities.

The results of this limited, but distinctive, study indicate an increased complexity for academic libraries and librarianship. If handled correctly, this may strengthen the positions of libraries within the context of the university organization, as well as in relation to their traditional users, the scholars and the students. If being able to formulate the benefits of bibliometrics to both university administration and to the research community, academic libraries might eventually take on a position more central in the development of the very universities within which they function, and thus put themselves at the very centre of higher learning - on the strong foundation of a confident profession.

\section{Funding}

This research received no specific grant from any funding agency in the public, commercial or not-for-profit sectors.

\section{Note}

1. http://istservice.lub.lu.se/mailman/listinfo/metrics

\section{References}

Åström F (2007) Changes in the LIS research front: Time-sliced co-citation analyses of LIS journal articles, 1990-2004. Journal of the American Society for Information Science and Technology 58(7): 947-957.

Ayris P (2011) University and research libraries in Europe working towards Open Access. Liber Quarterly 20(3/4): 332-346.

Ball R and Tunger D (2006) Bibliometric analysis: A new business area for information professionals in libraries? Scientometrics 66(3): 561-577.

Brennan P (2008) Library assessment: Changing roles for the academic library in support of academic research evaluation. Unpublished presentation at the 2008 Library assessment conference, Seattle, WA, 4-7 August 2008. Available at: http:// libraryassessment.org/bm doc/brennan.pdf (accessed 10 February 2012).

Carlsson H and Hällgren M (2008) Inventering av Bibliometrisk Verksamhet vid Svenska Lärosäten [Inventory of Bibliometric Activities at Swedish Institutions for Higher Education]. Report: Arbetsgruppen för Bibliometri: SUHF/Forum för Bibliotekschefer. Available at: http:/gupea.ub.gu.se/dspace/ bitstream/2077/18182/1/gupea_2077_18182_1.pdf (accessed 10 February 2012).

Dikeman RK (1975) Use of bibliometric techniques in serials management for libraries. Proceedings of the American Society for Information Science 12: 55-56.

Gerritsma W, Van Veller M and Van Zeist C, et al. (2010) Bibliometrics in the library: Putting science into practice [Abstract]. Book of Abstracts: STI Conference. Leiden, The Netherlands: Universiteit.

Hansson J (2010) Libraries and Identity: The Role of Institutional Self-Image and Identity in the Emergence of New Types of Libraries. Cambridge: Chandos.

Jimenez-Contreras E, De La, Moneda M and de Osma ER, et al. (2006) A bibliometric model for journal discarding policy at academic libraries. Journal of the American Society for Information Science and Technology 57(2): 198-207.

Kishida K (1995) Quantitative approaches to library management: A critical review. Library and Information Science 33: 39-69.

Narin F and Moll JK (1977) Bibliometrics. Annual Review of Information Science and Technology 12: 35-58.

Nicholson S (2003) The bibliomining process: Data warehousing and data mining for library decision making. Information Technology and Libraries 22 (4): 146-151.

Nolin J and Åström F (2010) Turning weakness into strength: Strategies for future LIS. Journal of Documentation 66(1): $7-27$.

Pendlebury DA (2009) Whitepaper: Using Bibliometrics: A Guide to Evaluating Research Performance with Citation Data. Philadelphia, PA: Thomson Reuters.

Schreiber T and Elbeshausen H (eds) (2006). Bibliotekarerne: En Profession $i$ et Felt af Viden, Kommunikation og Teknologi [The Librarians: A Profession within a Field of Knowledge, Communication and Technology]. Frederiksberg, Denmark: Samfundslitteratur.

Vanclay JK (2011) An evaluation of the Australian Research Council's journal ranking. Journal of Informetrics 5 (2): 265-274. 
White HD and Griffith BC (1981) Author co-citation: A literature measure of intellectual structure. Journal of the American Society for Information Science 32(3): 163-171.

White HD and McCain KW (1989) Bibliometrics. Annual Review of Information Science and Technology 24: 119-186.

White HD and McCain KW (1998) Visualizing a discipline: An author co-citation analysis of information science, 1972-1995. Journal of the American Society for Information Science 49(4): 327-355.

Whitley R and Gläser J (eds) (2007) The Changing Governance of the Sciences: The Advent of Research Evaluation Systems. Dordrecht: Springer.

Wilson CS (1999) Informetrics. Annual Review of Information Science and Technology 34: 107-247.

\section{Author biographies}

Fredrik Åström has a PhD in Library and Information Science and has since graduation held a position as Postdoctoral Research Fellow at Lund University. Åström has published internationally on topics such as citation analysis, research field visualization and the relation between scholarly communication and the general organization of research fields for more than 10 years, both within the LIS field and in other fields such as Science Policy and Innovation Studies. He is currently working as a scientometrics and scholarly communication specialist at Lund University Libraries; and frequently gives lectures on scientometrics and bibliometrics at various university departments and schools, for library associations and for organizations within the science and technology evaluation sector.

Joacim Hansson is Professor in Library and Information Science at Linnaeus University, Växjö, Sweden. He has published internationally for almost 20 years on a broad range of LIS topics, such as classification theory, information management, science methodology, and the scientific development of LIS as a research field. During the last couple of years he has mainly focused his research on institutional development and identity creation in library and information organizations. This research resulted, together with a string of articles, in the book Libraries and Identity: The Role of Institutional Self-Image in the Emergence of New Types of Libraries (Chandos, 2010). 